\title{
Improving of Geometric Precision in the Manufacture of Circular Holes Using Technology WEDM
}

\author{
L'. STRAKA ${ }^{1}, \mathrm{G}$. DITTRICH ${ }^{2}$
}

${ }^{1}$ Technical University of Kosice, Faculty of Manufacturing Technologies with a seat in Presov, Department of Automobile and Manufacturing Technologies, luboslav.straka@tuke.sk

${ }^{2}$ Technical University of Kosice, Faculty of Manufacturing Technologies with a seat in Presov, Department of Automobile and Manufacturing Technologies, gabriel.dittrich@tuke.sk

Abstract. WEDM technology is among the final technology. It is characterized by the high quality of the machined surface. Therefore, a small geometric deviation from the desired shape, position, orientation or run out may have a significant impact on the functionality of the finished component. Its range is largely influenced by the accuracy of the applied electroerosion device, the precision of the workpiece and tool setting, the machining method, but also the combination of each other and the adjustment of all process parameters. They result in the final quality of the machined surface not only in terms of roughness parameters but also in terms of geometric precision of the machined surface. The aim of the paper was to describe the possibilities of improving the geometrical accuracy of WEDM with thin brass electrodes. At the same time, it contributes to an existing database of knowledge that defines the influence of selected aspects on the geometrical accuracy of the machined area in the production of circular openings.

\section{Introduction}

It is generally known that the geometrical precision of the machined surface after WEDM is largely influenced by the precision [1] and the reliability of the CNC electro-erosion machine and the combination of adjustment of all process parameters [2,3]. These input factors are the creators of the resulting qualitative level of the machined surface [4]. Geometric accuracy as one of the qualitative indicators of the machined surface includes a series of criteria [5] that are applied to the final quality of the machined surface [6]. The inspection also requires adherence to the relevant technical standards, which are defined for the measurement of geometric deviations of the machined surface. This is in particular the standard STN EN ISO 1101: 2017-08, which describes Geometric Product Specifications (GPS) - tolerance of shape, orientation, position and run out.

\section{Causes of geometric accuracy of machined area after WEDM}

Generally, the geometric accuracy of machined area after WEDM can be quantified [7] by appropriate deviations from the nominal area. As mentioned earlier, these deviations of geometric accuracy are defined in detail by STN EN ISO 1101: 2017-08. This is in particular the deviations of shape, direction, 
position and run out [8]. The actual size of the geometric deviation of the machined surface [9] from the nominal (required) surface may affect the conventionally measured dimension even if the required dimensional tolerance is maintained. In practice, it is evaluated as the greatest distance of the points of a given area (profile) in the normal direction or as the sum of the absolute values of the greatest distances of the points of the given area (profile). The total final geometric precision of the machined surface after WEDM is the result of a number of acting factors. Each of them causes the characteristic initial geometrical inaccuracies of the machined surface.

Geometrical inaccuracies of the machined surface after WEDM are the most common:

$\checkmark$ caused by geometric and kinematic inaccuracies of the electro-erosion machine,

$\checkmark$ caused by flexible deformations of the technological system machine, tool, workpiece and the deformations of the wire electrode caused by the discharge,

$\checkmark$ caused by inadequate machine alignment and workpiece setting,

$\checkmark$ caused by thermal deformations [10] of the technological system,

$\checkmark$ caused by vibration of the technological system,

$\checkmark$ caused by geometric inaccuracies of the wire electrode [11],

$\checkmark$ caused by wear of the wire electrode,

$\checkmark$ caused by insufficient software management of the wire electrode,

$\checkmark$ caused by deformations of the workpiece from the clamping forces,

$\checkmark$ caused by internal stresses in the workpiece material,

$\checkmark$ caused by non-homogeneity of the structure of the machined material.

The geometric accuracy of the machined surface after WEDM depends on many factors [12]. However, it is largely influenced by the precision and reliability of a CNC electro-erosion machine and by a combination of process parameters [13]. These aspects as input factors are the creators of the resulting qualitative level of machined surface. On the geometric precision machined surface also it affects, e.g. vibration of the wire tool electrode. The vibration of the wire tool electrode during wire electrical discharge machining occurs as a result of an inappropriate combination of electrode and workpiece material, but also by setting of the technological parameters [14]. This unwanted effect during wire electrical discharge machining can be partially eliminated, e.g. by choosing a suitable combination of electrode and workpiece material [15], but also by reducing the speed of the wire electrode rewinding, by constantly stretching it to the desired size, decreasing the rinsing pressure [16], and the like. With respect to all these aspects, the geometric deviation of the precision of the machined surface at the precision WEDM is approximately $\pm 4 \mu \mathrm{m}$ to $\pm 10 \mu \mathrm{m}$. In the following Fig. 1 shows the mechanism of the geometric deviation of the machined surface in the precision WEDM. 

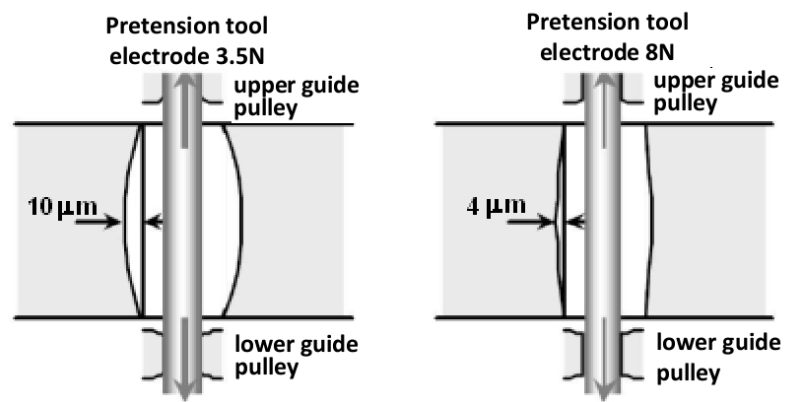

Figure 1. Mechanisms arise of geometric deviation of machined surface at precision WEDM.

As mentioned above, the geometrical precision of the machined surface after WEDM depends on many factors [17] and is quantified according to the standard by the respective deviations. These are mainly the deviations of the dimension $\Delta w$, the shape $\Delta s$ and the position $\Delta p$. Dimension deviation $\Delta w$ is one of the most important parameters when evaluating the geometric accuracy of a machined surface after WEDM. This is a parameter that describes the dimensional inaccuracy of the actual area with respect to the size of the nominal area. Generally, the deviation of the dimension $\Delta w$ after wire electrical discharge machining is constituted by a set of deviations, which describes the following relation (1):

$$
\Delta w=\delta_{D M}+\delta_{H E}+\delta_{M E}+\delta_{P P}+\delta_{C E}
$$

where:

$\delta_{D M}$ - represents a deviation which is mainly due to deformations and inaccuracy of individual parts of the CNC electro-erosion device. Since WEDM is among to the so-called without force machining, this deviation is almost insignificant. In practice, its size moves to $3.0 \mu \mathrm{m}$;

$\delta_{H E}$ - represents the deviation resulting from the heating of the wire tool electrode and the machined material during the electroerosion process. This deviation gains its importance especially in highperformance machining using the wire electrode tool of larger diameter. In case of application of wire tool electrodes of smaller diameters $\left(\phi_{\mathrm{e}} \leq 0.15 \mathrm{~mm}\right)$ with efficient cooling of the working space by dielectric fluid, this deviation is almost negligible;

$\delta_{M E}$ - represents the deviation which causes the manufacturing errors of the tool wire electrode. In practice, its size is within $2.0 \mu \mathrm{m}$;

$\delta_{P P}$ - represents the deviation that occurs due to inappropriate choice of process parameters. This deviation can be partly offset by appropriate optimization;

$\delta_{C E}-$ represents the deviation that arises from errors in the control of the wire tool electrode.

Deviation of the shape of machined surface $\Delta s$ after WEDM is determined by the difference in the shape of the actual surface with respect to its ideal shape. The deviations of the shape during WEDM include, in particular, the waviness of the machined surface, which is caused mainly by the oscillation of the machine-tool-workpiece system. In particular, when the wire tool electrode moves along the circular path during WEDM, the vibration amplitude of the wire tool electrode is substantially increased. This is mainly due to the effect of electrical discharges between the wire electrode and the workpiece, but also due to the flow of the dielectric fluid. This leads to a deterioration of the vast majority of indicators geometric accuracy of the machined surface. Another important parameter in evaluating the geometric machined area after WEDM is the deviation of the position $\Delta p$. It is a parameter that describes the inaccuracy of the relationship of two elements (surfaces, lines, points), 
on one workpiece or on multiple workpieces to each other. Its size during WEDM depends on the machining method, working conditions, accuracy and stiffness of the machine [18]. The following tab. 1 gives a basic overview of the magnitude of the geometric deviations of the machined surface in each WEDM method in terms of dimensional deviations.

\begin{tabular}{lc}
\hline \multicolumn{1}{c}{ WEDM method } & Geometric dimension deviation \\
\hline Precise finishing operations with a tool wire electrode $\left(\phi_{\mathrm{e}}<0.15 \mathrm{~mm}\right)$ & \pm 4.0 to $\pm 10.0 \mu \mathrm{m}$ \\
Fine operations with tool wire electrode $\left(\phi_{\mathrm{e}}<0.25 \mathrm{~mm}\right)$ & \pm 10.0 to $\pm 50.0 \mu \mathrm{m}$ \\
Standard operations with tool wire electrode $\left(\phi_{\mathrm{e}}=0.25 \mathrm{~mm}\right)$ & \pm 50.0 to $\pm 100.0 \mu \mathrm{m}$ \\
High-performance wire tool electrode of larger diameters $\left(\phi_{\mathrm{e}}>0.30 \mathrm{~mm}\right)$ & \pm 100.0 to $\pm 500.0 \mu \mathrm{m}$ \\
\hline
\end{tabular}

Table 1. Dimension volume of geometric deviations of the machined surface after WEDM.

\section{Material and methods of work}

The experimental samples were produced by applying electro-erosion machine Fanuc Alfa C600iA (Fig.2). It is a three-dimensional vertical CNC electro-erosion device that is used in practice for cutting metal materials. Its application is mainly in the production of complicated shear tools from hard-tomachinable materials.

\begin{tabular}{|l|l|}
\hline \multicolumn{1}{|c|}{ Basic device parameters } & \multicolumn{1}{c|}{ Maximum range } \\
\hline Max. Axis Travel X/Y/Z & $600 \times 400 \times 310 \mathrm{~mm}$ \\
\hline Max. Work Table Size & $1050 \times 820 \times 310 \mathrm{~mm}$ \\
\hline Max. Workpiece Weight & $1000 \mathrm{~kg}$ \\
\hline Speed rewinding wire & $0-15 \mathrm{~m} . \mathrm{min}^{-1}$ \\
\hline Diameters of the wire electrode & $0.10-0.30 \mathrm{~mm}$ \\
\hline Wire tension & $250-2500 \mathrm{~g}$ \\
\hline Total machine weight & $3050 \mathrm{~kg}$ \\
\hline Dielectric fluid (capacity) & $950 \mathrm{l}$ \\
\hline
\end{tabular}

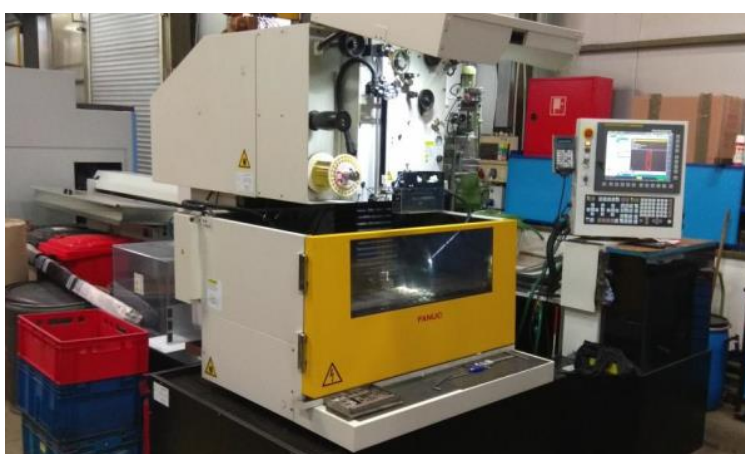

Figure 2. FANUC ALFA C600iA electro-erosion machine.

Thome Rapid CNC 3D measuring devices (Fig. 3) were used to measure circularity deviations on experimental samples.

\begin{tabular}{|l|l|}
\hline Basic device parameters & \multicolumn{1}{|c|}{ Maximum range } \\
\hline Axis Travel X/Y $/ \mathrm{Z}$ & $600 \times 500 \times 400 \mathrm{~mm}$ \\
\hline Resolution & $0,0001 \mathrm{~mm}$ \\
\hline Fast feed & $250 / 430 \mathrm{~mm} \cdot \mathrm{min}^{-1}$ \\
\hline Max. workpiece weight & $450 \mathrm{~kg}$ \\
\hline Air consumption & $25 \mathrm{l} \cdot \mathrm{min}^{-1}$ \\
\hline
\end{tabular}

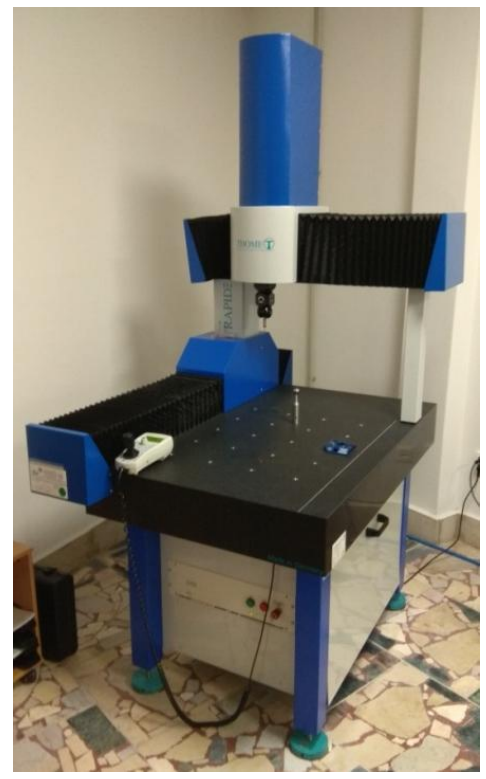

Figure 3. 3D measuring equipment Thome Rapid CNC. 


\section{Results of experimental measurements}

Based on the results of the experimental measurements of the maximum deviations of circularity of the machined surface using the Thome Rapid CNC measuring device, graphical dependencies were constructed. The following graph in Fig. 4 shows the dependence of the magnitude of the maximum geometric deviations of the circularity of the machined surface on the diameter of the hole in the range $\phi_{\mathrm{w}}=10.0-80.0 \mathrm{~mm}$ after WEDM with a brass wire electrode $\phi_{\mathrm{e}}=0.25 \mathrm{~mm}$.

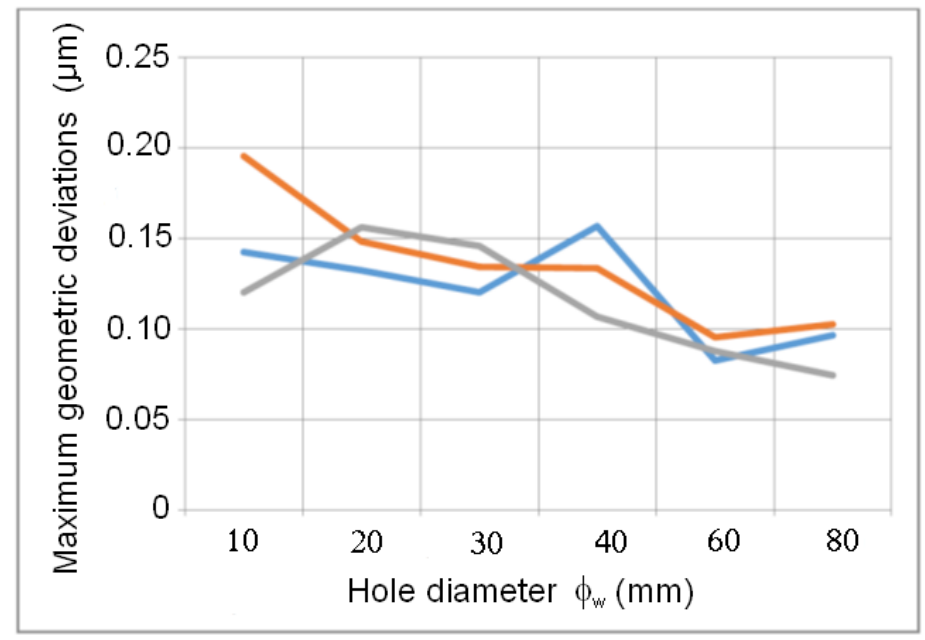

Figure 4. Dependence of the magnitude of the maximum geometric deviations of the circularity of the machined surface on the diameter of the hole in the range $\phi_{w}=10.0-80.0 \mathrm{~mm}$ after WEDM with a thin brass wire electrode

$$
\phi_{e}=0.25 \mathrm{~mm} \text {. }
$$

Based on the results of the experimental measurements of the maximum geometric deviations of the circularity of the machined surface shown in Fig. 4 can be observed trend of increasing their value in reducing the diameter of the holes. Increasing the maximum geometric deviation of circularity with reducing diameter $\phi_{w}$ is probably due to the interpolation errors with which the electro-erosion device works. These interpolation errors also cause the biggest problems in the production of small diameter holes $\phi_{w}$. Two solutions have been proposed to eliminate these deviations. The first design solution is suitable for producing relatively small hole diameters $\phi_{w} \leq 200.0 \mathrm{~mm}$. The design consists of housing, bearings, worm wheel that is powered by a servo motor. It is possible to directly implement it in the workspace of the electro-erosion machine. Its working opening has $\varnothing 250.0 \mathrm{~mm}$ with the external dimensions of the $500 \times 500 \mathrm{~mm}$ turntable and $127.0 \mathrm{~mm}$ height. Its design arrangement is shown in Fig. 5. 


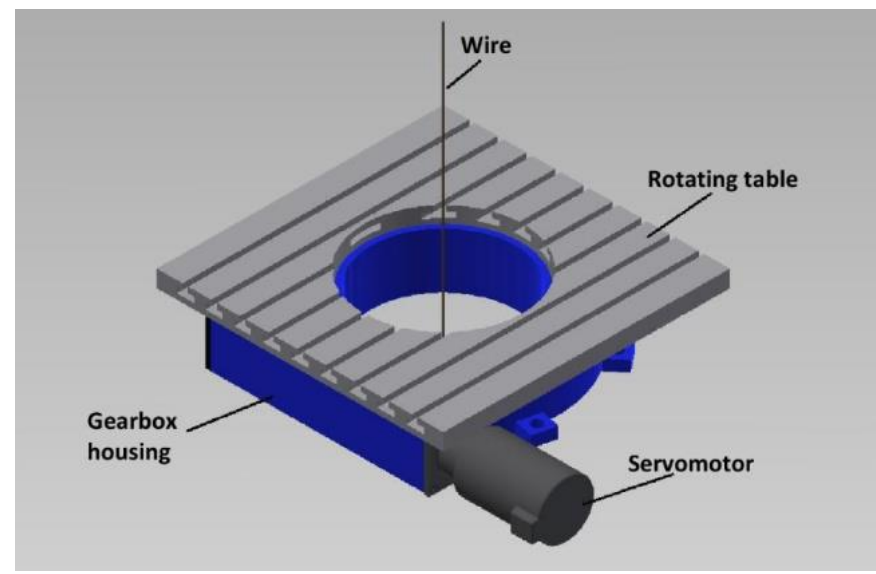

Figure 5. Design solution to eliminate geometric accuracy errors at WEDM holes with $\phi_{w} \leq 200.0 \mathrm{~mm}$.

The main advantage of a given design solution for production of round holes by WEDM technology is the possibility of producing relatively small diameters $\phi_{w}$, where the circle variation is the largest. Another advantage is the possibility of clamping the workpieces with larger dimensions. However, the main disadvantage of a given design solution is the relatively difficult setting of the workpiece on its work table.

The second design solution is suitable for making holes with $\phi_{w} \geq 50.0 \mathrm{~mm}$. It consists of a servo motor and a work table. The diameter of the rotary table is $\phi 45.0 \mathrm{~mm}$ and its height is $10.0 \mathrm{~mm}$. This table has a built-in electromagnet, since implementation of another clamping method would be complicated. The servo motor has dimensions $100 \times 100 \mathrm{~mm}$ and height $190.0 \mathrm{~mm}$ of a given design solution is its relatively fast implementation on the work table of the electro-erosion machine. Its design arrangement is shown in Fig. 6.

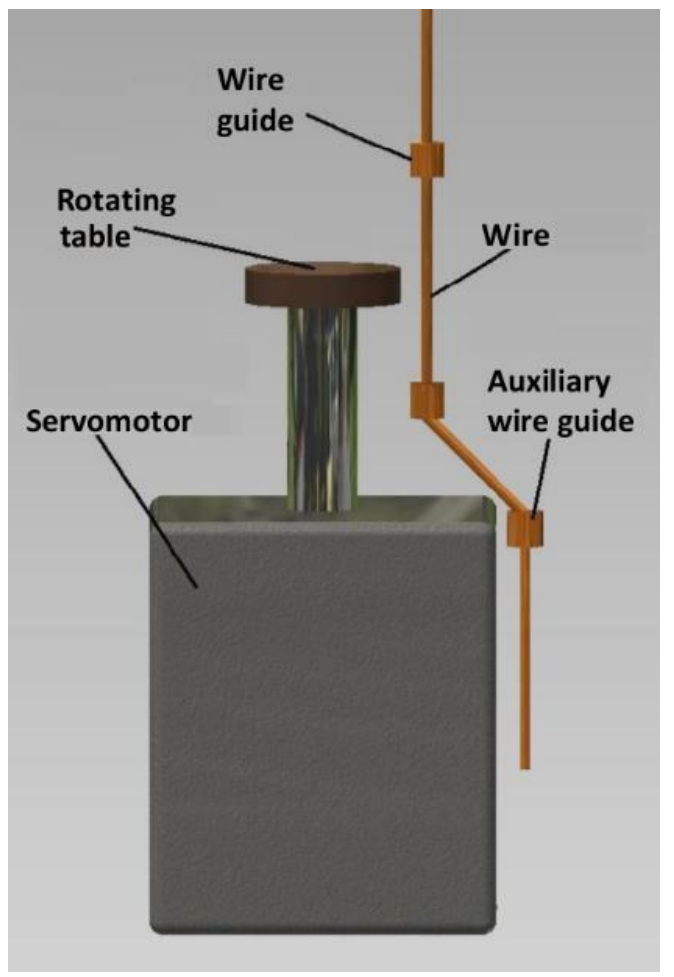

Figure 6. Design solution to eliminate geometric accuracy errors at WEDM holes with $\phi_{w} \geq 50.0 \mathrm{~mm}$. 
The main advantage of a given design to eliminate geometric precision errors in WEDM holes is its simple implementation into existing electroerosive devices, disposition compactness and easy operation and maintenance. However, the main disadvantage of the given design is the limitation of the lower limit of the produced holes $\phi_{w} \geq 50.0 \mathrm{~mm}$ and the need to implement the auxiliary lead of the wire electrode.

\section{Conclusion}

WEDM technology has been developing extremely rapidly in recent years. This development is decisively influenced by the application of high-performance electro-erosive devices using special wire electrodes. The type and quality of the wire electrode material have a decisive influence on the quality of the machined surface. In order to achieve optimal results, the highest precision of wire conduction is also necessary for the precision and quality of machined surfaces. In addition to the geometrical inaccuracies that arise from the electrical discharge between the wire electrode and the workpiece, it is deflected from the ideal position, i.e., the desired location caused by inaccurate hardware and software management. With the increasing thickness of the workpiece and the decreasing radius of curvature, its deflection is even greater. The aim of the paper was to describe possibilities for eliminating the maximum deviation of circularity in the production of WEDM round holes with a thin brass electrode. At the same time, it contributes to an existing database of knowledge that defines the influence of selected aspects on the maximum geometric deviation of the circularity of the machined surface at WEDM circular apertures. Designed solutions for the production of holes are applicable to most of the currently used electro-erosion devices. This solution will allow you to eliminate the main drawback of the inaccuracy of interpolation. When connected to the machine control system, it will form one compact unit.

\section{Acknowledgments}

The research work is supported by the VEGA Grants No. 1/0381/15 and by the KEGA Grant No. 004 TUKE-4/2017.

\section{References}

[1] S. Hašová - L. Straka (2006) Design and verification of software for simulation of selected quality indicators of machined surface after WEDM. Academic Journal of Manufacturing Engineering. 14 (2) pp. 13-2, ISSN 1583-7904.

[2] T. Chen, et al. (2017) Study on test method of white layer microhardness in hard cutting based on chord tangent method. International Journal of Advanced Manufacturing Technology. 92(1-4) pp. 733-741.

[3] S. Mathew - P.R.D. Varma - P.S. Kurian (2014) Study on the Influence of process parameters on surface roughness and MRR of AISI 420 stainless steel machined by EDM. Int. J. Eng. Trends Technol. 2. pp. 54-58. 
[4] P. Malega (2017) Simulation of production systems as the effective tool of efficiency increasing. Interdisciplinarity in theory and practice. 12. pp. 17-22.

[5] A. Mičietová - M. Neslušan - M. Čilliková (2013) Influence of surface geometry and structure after non-conventional methods of parting on the following milling operations. Manuf. Technol.13. pp. 199-204.

[6] P. Michalik - J. Zajac - M. Hatala - J. Duplák - D. Mital' (2016) Comparison of programming production of thin walled parts using different CAM systems. MM Science journal. 10. pp. 10561059. ISSN 1803-1269.

[7] M. Neslušan, et.al. (2007) Experimental methods in splinter machining. EDIS ŽU Žilina. pp. 343, ISBN 978-80-8070-711-8.

[8] P.P. Monka - K. Monková - M. Balara - S. Hloch - J. Rehor - A. Andrej - M. Šomšák (2016) Design and experimental study of turning tools with linear cutting edges and comparison to commercial tools. The International Journal of Advanced Manufacturing Technology. 85 (9-12) pp. 23252343. ISSN 0268-3768.

[9] A. Panda - M. Prislupčák - I. Pandová (2014) Progressive technology diagnostic and factors affecting to machinability. Applied Mechanics and Materials. 616 pp. 183-190. ISSN 1660-9336.

[10] A. Panda - J. Duplák - M. Hatala - T. Krenický - P. Vrábel (2016) Research on the durability of selected cutting materials in the process of turning carbon steel. MM Science Journal. pp. 10861089, ISSN 1803-1269.

[11] J.S, Soni - G. Chakraverti (1995) Effect of electrode material properties on surface roughness and dimensional accuracy in electro-discharge machining of high carbon high chromium die steel. J. Ind. Eng. 76. pp. 46-51.

[12] L. Straka (2014) Analysis of Wire-Cut Electrical Discharge Machined Surface. LAP Lambert Academic Publishing, Germany. 98 p., ISBN 978-3-659-64435-1.

[13] L'. Straka - S. Hašová (2016) Assessing the influence of technological parameters on the surface quality of steel MS1 after WEDM, MM Science Journal. 11. pp. 1194-1200, ISSN 1803-1269.

[14] A.T. Salcedo - P.I. Arbizu - C.J.L. Perez (2017) Analytical modelling of energy density and optimization of the EDM machining parameters of inconel 600. Metals. 7 (5) pp.166.

[15] L'. Straka - I. Čorný - J. Pitel' (2016) Properties evaluation of thin microhardened surface layer of tool steel after wire EDM. Metals. 6 (5) pp. 1-16, ISSN 2075-4701.

[16] L'. Straka - I. Čorný - J. Pitel' - S. Hašová (2017) Statistical Approach to Optimize the Process Parameters of HAZ of Tool Steel EN X32CrMoV12-28 after Die-Sinking EDM with SF-Cu Electrode, Metals. 7 (2) pp. 1-22, ISSN 2075-4701.

[17] R. Świercz - D. Oniszczuk-Świercz (2017)Experimental Investigation of Surface Layer Properties of High Thermal Conductivity Tool Steel after Electrical Discharge Machining. Metals. 7 (12) p. 550.

[18] S.K. Tamang - N. Natarajan - M. Chandrasekaran (2017) Optimization of EDM process in machining micro holes for improvement of hole quality. J Braz. Soc. Mech. Sci. Eng. 39. pp. 12771287. 